\title{
Overweight/obesity and hypertension in schoolchildren aged 6-16 years, Aden governorate, Yemen, 2009
}

M.A.H. Badi, ${ }^{1}$ B.E. Garcia-Triana ${ }^{2,3}$ and R. Suarez-Martinez ${ }^{1,3}$

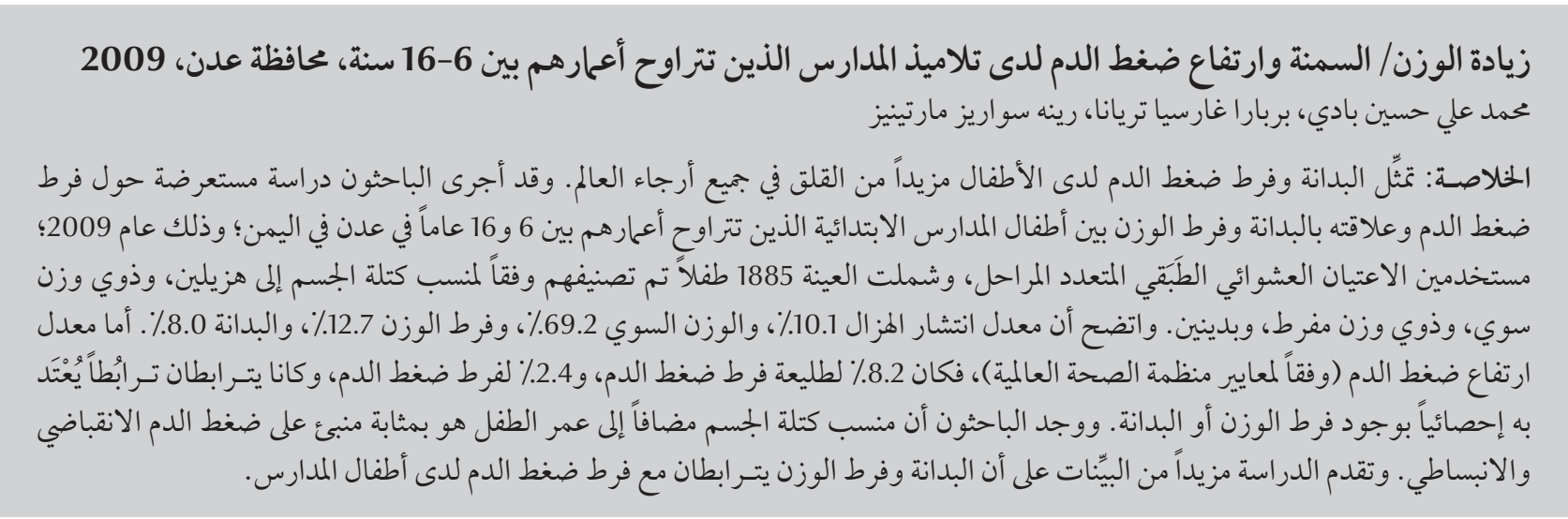

ABSTRACT Hypertension and obesity in children are increasing concerns worldwide. A cross-sectional study of hypertension in relation to overweight/obesity was conducted in 2009 among schoolchildren aged 6-16 years in Aden, Yemen. Using multistage stratified random sampling 1885 children were classified into wasted, normal weight, overweight and obese according to body mass index. The prevalence of wasting was $10.1 \%$, normal weight $69.2 \%$, overweight $12.7 \%$ and obesity $8.0 \%$. The rate of high blood pressure (World Health Organization criteria) was $8.2 \%$ for prehypertension and $2.4 \%$ for hypertension and was significantly related to the presence of overweight or obesity. Child's body mass index combined with age was a predictor for systolic and diastolic blood pressure. The study provides further evidence that overweight/obesity is associated with hypertension in these schoolchildren.

Surcharge pondérale, obésité et hypertension chez des élèves âgés de 6 à 16 ans et scolarisés dans le gouvernorat d'Aden (Yémen) en 2009

RÉSUMÉ L'hypertension et l'obésité chez les enfants sont des préoccupations croissantes dans le monde. Une étude transversale sur l'hypertension en relation avec la surcharge pondérale et/ou l'obésité a été menée en 2009 auprès d'élèves âgés de 6 à 16 ans à Aden (Yémen). Un échantillon aléatoire stratifié à plusieurs degrés de 1885 enfants a été réparti en fonction de leur indice de masse corporelle dans les catégories suivantes : émaciation, poids normal, surcharge pondérale ou obésité. La prévalence de l'émaciation était de 10,1\%, d'un poids normal de 69,2\%, d'une surcharge pondérale de 12,7\% et d'une obésité de 8,0 \%. Les taux de I'hypertension selon les critères de l'Organisation mondiale de la Santé, étaient de 8,2 \% pour la préhypertension et de 2,4\% pour l'hypertension. Ceux-ci étaient fortement liés à une surcharge pondérale ou une obésité. L'indice de masse corporelle des enfants associé à l'âge était un facteur prédictif de tension artérielle systolique ou diastolique. L'étude fournit aussi d'autres preuves qu'une surcharge pondérale et/ou une obésité sont associées à une hypertension chez les élèves.

'Department of Community Medicine and Public Health; ${ }^{2}$ Department of Physiological Sciences, Faculty of Medicine, University of Aden, Aden, Yemen (Correspondence to M.A.H. Badi: mohamedbadi1@yahoo.com).

${ }^{3}$ Havana Medical Sciences University, Havana, Cuba.

Received: 20/01/11; accepted: 03/04/11 


\section{Introduction}

Overweight and obesity are linked to serious health consequences, notably cardiovascular diseases, which are the world's number one cause of death in developed as well as in developing countries [1]. Studies have shown that obese people have a 5 times greater incidence of hypertension than those of normal weight $[2,3]$. The obesity epidemic has also been linked to an increase in the number of children with high blood pressure. Scientists in the United States (US) found that while more than $3 \%$ of children studied had high blood pressure, three-quarters of them had not been properly diagnosed [4]. Around 30\% of overweight children have abnormal blood pressure. Therefore, weight loss is the initial treatment choice for high blood pressure in children [5].

In a developed country such as the US, more than 4 million children are estimated to have hypertension, a number that has increased 5-fold over the last 30 years, and has been linked to growing obesity in children among other factors [6]. The same pattern has been found in developing countries; for example in India the prevalence of hypertension in overweight schoolchildren was significantly higher than that among normal weight children [7]. An emerging double burden of both malnutrition and obesity has also been identified in developing countries. This poses the possibility that such an association could also be present in Aden, a city in southern Yemen, where there is a lack of data about these issues. The aim of the present study was to investigate the relationship between overweight/obesity and high blood pressure levels in primary-school children from Aden governorate. The results of the study will help to design programmes for the prevention and control of the disease in childhood, which could decrease the impact of chronic disease in adulthood.

\section{Methods}

This was an observational, cross-sectional study, conducted in Aden governorate, Yemen. The data collection period was from February to December 2009. Approval for the study was obtained from the Faculty of Medicine and local authorities. Informed consent was obtained from the parents for their children to be enrolled in the study.

\section{Sample}

The study subjects were chosen from the target population that included all of primary-school children of Aden governorate aged between 6 and 16 years (108982 children) [unpublished data, Ministry of Education, Aden, Yemen]. In Yemen, primary school (basic) education start at age 6 years and continues for 9 years. From the total of 130 schools, 8 schools were selected using multistage stratified random sampling, with attention to proportional allocation by type of school (public or private), in each geographical area of the city, to obtain a representative sample of the target population. The schools were numbered and chosen using random tables. One class from each level was randomly chosen in the selected schools. The children were selected from each school record by systemic random sampling technique. After taking into account a possible $20 \%$ non-response rate and with 95\% confidence, the sample size was calculated to be 1953 students, who were selected from 6 public and 2 private schools from 4 district of Aden governorate (AlMansora, Shaikh-Othman, Dar Sad and KhorMakser) [8]. From 1953 students given consent forms, 1885 consented and participated in the study ( $96.5 \%$ of response rate).

\section{Data collection}

The measurements of body weight and height were carried out by the researcher assisted by medical assistants in the school. Body weight was measured to the nearest $0.1 \mathrm{~kg}$ using an electronic scale (Seca, Japan). Body height was measured to the nearest $0.5 \mathrm{~cm}$ using a stadiometer (Seca, Germany) as the child stood erect against a vertical wall, in the Frankfort plane according to the published data [9]. Body mass index (BMI) was calculated as the ratio of the body weight to the square of body height $\left(\mathrm{kg} / \mathrm{m}^{2}\right)$, and was classified into 4 categories to assess nutritional status as: wasted $(<3 \mathrm{rd}$ percentile), normal weight $(\geq 3 \mathrm{rd}-<85$ th percentile), overweight ( $\geq 85$ th $-<97$ th percentile) and obese ( $\geq 97$ th percentile). This classification was in accordance with the recommendations of the World Health Organization (WHO) Expert Committee in Overweight, and the 2007 WHO growth reference standards [10]. Twenty students (not included in the studied sample) were measured to calculate the intra-observer technical error of measurement. The range of values (0.1-0.3 for weight and 0.001-0.013 for height) were within the acceptable range [11].

Blood pressure was recorded twice by the researcher, and the value of the average systolic/diastolic blood pressure was classified according to the tables with cutoff points for each age, sex and height percentile as: normal (average systolic and diastolic blood pressure $<90$ th percentile), prehypertension ( $\geq 90$ th $-<$ 95th percentiles) and hypertension ( $\geq 95$ th percentile) [12]. The blood pressure manometers used a cloth cuff with an inflatable rubber chamber. The widest chamber was used to increase the validity of the measurement. The chamber was wrapped around $80 \%$ to $100 \%$ of the right arm circumference, measured at the average point between the acromion and the olecranon, leaving the elbow bend and the axillary region free. Its height corresponds to $40 \%$ of this circumference. The sitting blood pressure measurement was taken twice by electronic scale, and the average values were recorded [13]. 


\section{Data analysis}

Data were processed and analysed using SPSS software, version 15. The chi-squared test, with a significance level of $5 \%(P<0.05)$ was used to determine the possible relationship between overweight/obesity and blood pressure levels between the children.

\section{Results}

The 1885 schoolchildren participants were aged between 6 to 16 years (mean age 10.9 years). The results for nutritional status showed that overall 190 children (10.1\%) were wasted, 1305 (69.2\%) normal weight, 239 (12.7\%) overweight and 151 (8.0\%) obese,

From the total study group, $8.2 \%$ of the children had blood pressure levels defined as prehypertension and $2.4 \%$ as hypertension. Although the rate of prehypertension was slightly higher for females ( $9.4 \%$ versus $7.1 \%$ in males), for hypertension the results were similar ( $2.3 \%$ for males and $2.4 \%$ for females). There was no statistically significant relationship between sex and blood pressure in these children (Table 1).

There was a statistically significant relationship, however, between age group and the rate of prehypertension and hypertension $(P<0.05)$. In general, the proportion of children with normal blood pressure level in each age group was greater than those with prehypertension and hypertension. The rate of hypertension in children aged $6-9$ years and $10-12$ years $(3.1 \%$ and $3.4 \%$ respectively) was significantly higher than those aged $>12$ years $(0.8 \%)$. In addition, the rate of prehypertension was lower in those aged $10-12$ years $(7.6 \%)$ compared with those aged 6-9 years and $>12$ years ( $8.4 \%$ and $8.6 \%$ respectively) (Table 1 ).

There was a statistically significant relationship between the blood pressure levels and the presence of overweight/ obesity in children $(P<0.05)$. Children who were overweight/obese showed a higher rate of prehypertension (21.8\%) than those who were wasted/normal weight (4.7\%). This was also true for hypertension (10.0\% among overweight/ obese children versus $0.4 \%$ for wasted/ normal children) (Figure 1).

When linear regression analysis was applied it showed a linear relationship between child's BMI and age as predictor variables for both systolic and diastolic blood pressure (Table 2). The values of the multiple correlation coefficients $(R)$ that indicate the strength of the association were 0.54 for systolic blood pressure and 0.41 for diastolic blood pressure; and the relationship was statistically significant $(P<0.05)$. The child's BMI made a higher contribution than child's age for both measures of blood pressure as the correspondent standardized coefficients show $(0.37$ for systolic blood pressure and 0.30 for diastolic blood pressure versus 0.24 and 0.15 respectively for child's age). According to the values of the coefficients $R^{2}$, child's age and child's BMI explained around one-third of the variation in the model for systolic blood pressure $\left(R^{2}=\right.$ $0.29)$ and around one-sixth of the variation in the model for diastolic blood pressure $\left(R^{2}=0.16\right)$ (Table 2).

\section{Discussion}

The results of the present study demonstrated that the overall prevalence of wasting among primary-school children from Aden governorate was high (10.1\%). On the other hand, the prevalence of overweight and obesity were also high (12.7\% and 8.0\%, respectively), as an expression of the double burden of disease that has been described for malnutrition in underdeveloped countries [14].

In general the study showed that the rate of abnormal blood pressure was higher, although not significant, in girls than in boys; this could be explained by the hormonal modifications related to puberty, which starts earlier among girls than among boys [15]. This agrees with some researches in Kuwait, India $[16,17]$. There was a significant relationship between age group and frequency of high blood pressure, with higher rates of hypertension in those aged 6-9 years and 10-12 years in this study. This is in

\begin{tabular}{|c|c|c|c|c|c|c|c|c|c|}
\hline \multirow[t]{3}{*}{ Variable } & \multirow{3}{*}{$\begin{array}{c}\text { Total } \\
\text { No. }\end{array}$} & \multicolumn{6}{|c|}{ Blood pressure level } & \multirow[t]{3}{*}{$x^{2}$} & \multirow[t]{3}{*}{$P$-value } \\
\hline & & \multicolumn{2}{|c|}{ Normal } & \multicolumn{2}{|c|}{ Prehypertension } & \multicolumn{2}{|c|}{ Hypertension } & & \\
\hline & & No. & $\%$ & No. & $\%$ & No. & $\%$ & & \\
\hline Sex & & & & & & & & 3.25 & 0.197 \\
\hline Male & 981 & 888 & 90.5 & 70 & 7.1 & 23 & 2.3 & & \\
\hline Female & 904 & 797 & 88.2 & 85 & 9.4 & 22 & 2.4 & & \\
\hline Age group (years) & & & & & & & & 11.54 & 0.021 \\
\hline 6-9 & 643 & 569 & 88.5 & 54 & 8.4 & 20 & 3.1 & & \\
\hline $10-12$ & 593 & 528 & 89.0 & 45 & 7.6 & 20 & 3.4 & & \\
\hline$>12$ & 649 & 588 & 90.6 & 56 & 8.6 & 5 & 0.8 & & \\
\hline Total & 1885 & 1685 & 89.4 & 155 & 8.2 & 45 & 2.4 & & \\
\hline
\end{tabular}


$\square$ Wasted/normal $(n=1495)$

- Overweight/obese $(n=390)$

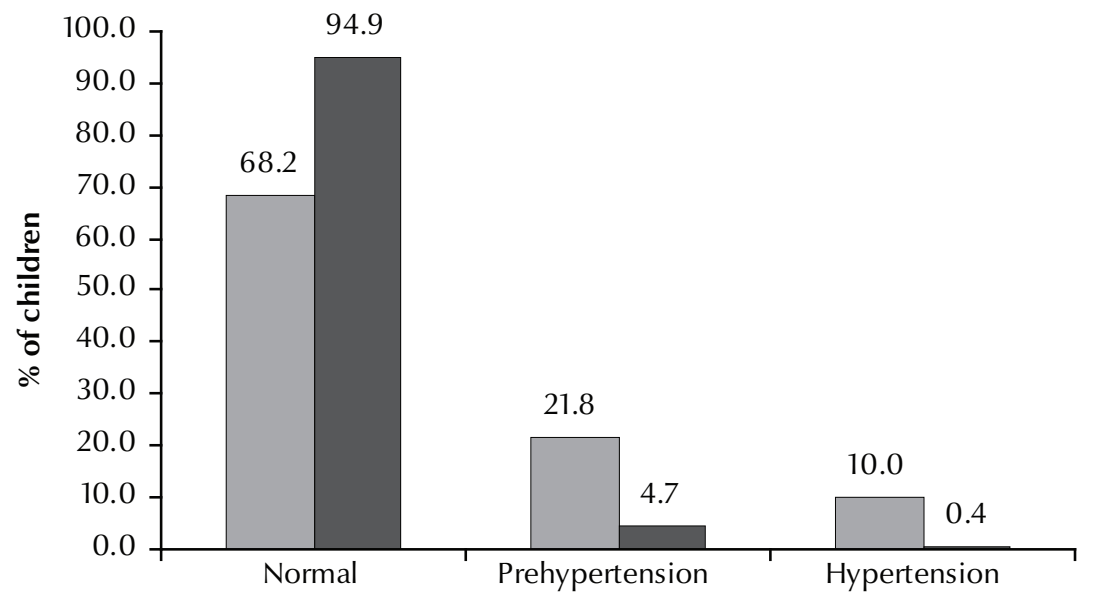

Figure 1 Relationship between nutritional status and blood pressure in primaryschool children in Aden governorate, Yemen

agreement with one study in Germany [18].

Our study showed a statistically significant relationship between the presence of overweight/obesity and increased blood pressure in students. Increased blood pressure (prehypertension or hypertension) was present in $31.8 \%$ of overweight/obese children and this corresponds to other articles, which reported that $30 \%-35 \%$ of overweight/obese children had abnormal blood pressure $[5,17,19]$. Some researchers reported a relationship between hypertension in schoolchildren and consanguineous parents, family history of hypertension and obesity $[16,20]$. Hypertension was linked to sedentary lifestyles, altered eating habits, high fat content of the diet and low physical activity, but also possibly to genetic factors.

BMI is associated with blood pressure, as confirmed in the present study by the presence of a linear relationship, with child BMI and age combined as predictor variables of systolic and diastolic blood pressures. Both factors explained around one-third and onesixth of the association in the models for systolic blood pressure and diastolic blood pressure respectively. This suggests that other factors may have influenced trends in blood pressure over time. Such factors may include nutrition characteristics, such as the intake

\begin{tabular}{|c|c|c|c|c|c|c|}
\hline \multirow[t]{2}{*}{ Variable } & \multicolumn{3}{|c|}{ Systolic blood pressure } & \multicolumn{3}{|c|}{ Diastolic blood pressure } \\
\hline & $B$ & $\beta$ & $P$-value & $B$ & $\beta$ & $P$-value \\
\hline Child's age & 0.79 & 0.24 & $<0.001$ & 0.41 & 0.15 & $<0.001$ \\
\hline Child's BMI & 0.81 & 0.37 & $<0.001$ & 0.54 & 0.30 & $<0.001$ \\
\hline$R$ & - & 0.54 & & - & 0.40 & - \\
\hline$R^{2}$ & - & 0.29 & & - & 0.16 & - \\
\hline Constant & - & 81.2 & & - & 49.7 & - \\
\hline
\end{tabular}

$B=$ coefficient of the linear regression (unstandardized); $\beta=$ standardized coefficient $R=$ multiple correlation coefficient.

Equations: Systolic blood pressure $=0.81($ BMI $)+0.75($ age $)+81.2$. Diastolic blood pressure $=0.54($ BMI $)+0.41$ (age) +49.7 . of fruits, vegetables or dairy products or salt. According to the literature, whereas the total calorie intake has increased greatly in most countries worldwide, mixed trends (favourable and unfavourable) have been observed for specific nutrients that relate to hypertension [21]. There are no published data about these factors in the study group of Yemeni primary-school children.

Secular changes in non-dietary factors may also have impacted on the trends in elevated blood pressure over time according to the literature. Studies have shown that low birth weight is associated with elevated blood pressure in adults and children [22]. Increased stature of mothers, favourable changes in socioeconomic factors and other factors such as improved maternal nutrition can be related to increased blood pressure [21]. Breastfeeding has been related to lower blood pressure in children, which can be a result of the low salt content and high long-chain polyunsaturated fatty acid content of breastmilk [23]. Finally, in many countries, the amount of reported physical activity (particularly walking time or leisure exercise) has generally decreased [21]. In addition to being a risk factor for obesity (itself related to elevated blood pressure), low physical activity has been associated independently with higher blood pressure in children [24]. Again, there are no published data about these issues in the study population. So, future research should focus on identify the factors which are causing the increased prevalence of overweight and associated high blood pressure in primary-school children from Aden.

\section{Conclusion}

This study showed that the prevalence of overweight and obesity were high in this population. In addition, the rates of high blood pressure, expressed as prehypertension and hypertension, were associated overweight and obesity 
of the children. The rate of abnormal blood pressure was higher in children aged 6-12 years while the child' sex had no effect in this population. The child's BMI combined with age could predict systolic and diastolic blood pressure in these children. The results confirmed that BMI was associated with blood pressure, implying that weight loss is a useful intervention in children with hypertension.

Blood pressure levels should be assessed regularly in children and adolescents, and studies should be conducted to determine the prevalence of high blood pressure in this group nationwide. Unless effective procedure and preventive strategies are instituted at the local and national level, these data may predict a possible rise in cardiovascular disease in adults in future decades.

\section{References}

1. Obesity and overweight. Geneva, World Health Organization, 2006 [online factsheet] (http://www.mclveganway.org.uk/ Publications/WHO_Obesity_and_overweight.pdf, accessed 28 April 2012).

2. Kearney PM et al. Global burden of hypertension: analysis of worldwide data. Lancet, 2005, 365:217-223.

3. Haslam DW, James WP. Obesity. Lancet, 2005, 366:1197-1209.

4. Hansen ML, Gunn PW, Kaelber DC. Underdiagnosis of hypertension in children and adolescents. Journal of the American Medical Association, 2007, 298:874-879.

5. Sorof JM et al. Isolated systolic hypertension, obesity, and hyperkinetic hemodynamic states in children. Journal of Pediatrics, 2002, 140:660-666.

6. Brady TM, et al. Patient-, provider-, and clinic-level predictors of unrecognized elevated blood pressure in children. Pediatrics, 2010, 125:e1286

7. Raj $M$ et al. Obesity in Indian children: time trends and relationship with hypertension. National Medical Journal of India, 2007, 20:288-293.

8. Kish L. Survey sampling. New York, John Wiley, 1965:398401.

9. National Health and Nutrition Examination Survey (NHANES) Anthropometry procedures manual. Rockville, Maryland, Centers for Disease Control and Prevention, 2009.

10. Growth reference data for 5-19 years. Geneva, World Health Organization, 2007 [online database] (http://www.who.int/ growthref/en/, accessed 28 April 2012).

11. Ulijaszek SJ, Kerr DA. Anthropometric measurement error and the assessment of nutritional status. British Journal of Nutrition, 1999, 82:165-177.

12. Falkner B, Daniels SR. Summary of the fourth report on the diagnosis, evaluation, and treatment of high blood pressure in children and adolescents. Hypertension, 2004, 44:387-388.
13. Pio da AC. Rosa AA. Blood pressure and obesity of children and adolescents: association with body mass index and waist circumference. Archivos Latinoamericanos de Nutrición, 2006, 56(3):244-251.

14. Warraich HJ et al. Prevalence of obesity in school-going children of Karachi. PLoS ONE, 2009, 4:e4816.

15. Harrabi I et al. Epidemiology of hypertension among a population of school children in Sousse, Tunisia. Canadian Journal of Cardiology, 2006, 22:212-216.

16. Saleh EA et al. Hypertension and its determinants among primary-school children in Kuwait: an epidemiological study. Eastern Mediterranean Health Journal, 2000, 6:333-337.

17. Mohan B et al. Prevalence of sustained hypertension and obesity in urban and rural school going children in Ludhiana. Indian Heart Journal, 2004, 56:310-314.

18. Gelbrich $\mathrm{G}$ et al. Prevalence of obesity and elevated blood pressure as well as onset of puberty in German school children attending different educational tracks. Hormone Research, 2008, 70:340-348.

19. Mavrakanas TA et al. Childhood obesity and elevated blood pressure in a rural population of northern Greece. Rural and Remote Health, 2009, 9:1150.

20. Krebs NF et al. Assessment of child and adolescent overweight and obesity. Pediatrics, 2007, 120(Suppl. 4):S193-S228.

21. Chiolero A et al. Has blood pressure increased in children in response to the obesity epidemic? Pediatrics, 2007, 119:544-553.

22. Law CM et al. Body size at birth and blood pressure among children in developing countries. International Journal of Epidemiology, 2001, 30:52-57.

23. Couch SC, Daniels SR. Diet and blood pressure in children. Current Opinion in Pediatrics, 2005, 17:642-647.

24. Andersen LB et al. Physical activity and clustered cardiovascular risk in children: a cross-sectional study (The European Youth Heart Study). Lancet, 2006, 368:299-304. 